\title{
SUPERAÇÃO DA DORMÊNCIA DE SEMENTES DE CARRAPICHO-BEIÇO-DE-BOI1
}

\author{
CIBELE C. MARTINS ${ }^{2}$, CRISTINA G. MENDONÇA ${ }^{3}$, DAGOBERTO MARTINS ${ }^{4}$ e EDIVALDO D. VELINI ${ }^{4}$
}

\begin{abstract}
RESUMO
Visando a obtenção de um tratamento para acelerar a germinação de sementes de Desmodium tortuosum ( $S$ w.) DC., foram realizados dois experimentos, nos quais, segmentos unisseminados de lomentos (testemunha) foram submetidos a debulha manual; debulha manual seguida por escarificação manual empregando-se lixa $n^{\circ} 220$; debulha mecânica (processador doméstico); escarificação química com $\mathrm{H} 2 \mathrm{SO} 4(95 \%)$ por 1,5 e 8 mim pré-aquecimento à $53^{\circ} \mathrm{C}$ por 4,10 e $16 \mathrm{~h}$ em estufa com circulação forçada de ar; embebição, utilizando-se $\mathrm{H}, 0$ à $80^{\circ} \mathrm{C}$ por $1,3,5$ e $10 \mathrm{~min} ; \mathrm{H}_{2} 0$ à $27^{\circ} \mathrm{C}$ por $2 \mathrm{~h}$ e embebição com alternância térmica $(\mathrm{H}, 0$ à $80^{\circ} \mathrm{C} / 5 \mathrm{~min}$ e $\mathrm{H}_{2} \mathrm{O}$ à $\left.13{ }^{\circ} \mathrm{C} / 1 \mathrm{~min}\right)$. Para a aval iação dos tratamentos fora $\mathrm{m}$ empregados os testes de germinação, de emergência de plântulas em solo (E), de primeira contagem de germinação (PG) e de emergência (PE), índices de velocidade de germinação (I.V.G.) e de emergência (I.V.E.), e o comprimento de plântulas $(\mathrm{CP}) .0$ delineamento estatístico adotado foi o inteiramente casualizado com 4 repetições de

ou 100 sementes (E, PE, I.V.E.) no segundo ex perimento. No primei ro ex perimento, os tratamentos que provocaram significativa redução da dormência (D) e, consequente elevação da germinação $(\mathrm{G})$, em comparação à testemunha $(\mathrm{D}=82 \% ; \mathrm{G}=15 \%)$ foram, em ordem decrescente de eficácia: debulha e escarificação manuais $(\mathrm{D}=3 \% ; \mathrm{G}=92 \%)$, debulha mecânica $(\mathrm{D}=13 \%$; $\mathrm{G}=81 \%$ ), embebição em $\mathrm{H}_{2} 0$ à $80^{\circ} \mathrm{C}$ por $1 \mathrm{~min}$ $(\mathrm{D}=68 \% ; \mathrm{G}=29 \%)$ e por $3 \mathrm{~min}(\mathrm{D}=65 \% ; \mathrm{G}=$ $32 \%$ ). No segundo experimento, (testemunha com $\mathrm{D}=93 \%$ e $\mathrm{G}=3 \%$ ) destacaram-se: debulha e escarificação manuais $(\mathrm{D}=2 \% ; \mathrm{G}=93 \%)$, debulha mecânica $(D=2 \% ; G=87 \%)$, embebição em $\mathrm{H} 20$ à $80^{\circ} \mathrm{C}$ por $5 \mathrm{~min}$ e alternância térmica (ambos com $\mathrm{D}=85 \%$ e $\mathrm{G}=11 \%$ ). 0 s testes de vigor PC, I.V.G., I.V.E., CP, e E corroboraram ess es resultados. 0s métodos de esc ari fic ação manual com lixa 220 e de bu lha me cânica, empregando-se processador, podem ser recomendados para a superação da dormência e promoção da germinação de sementes de $D$. tortiosum.
\end{abstract} 100 (G, PG, I.V.G.) ou 20 se mentes (CP) por tratamento no primeiro experimento e 4 repetições de 50 (G, PG, I.V.G.)
Palavras chave: Desmodium tortuosum, planta daninha, germinação, emergência.

\section{ABSTRACT}

\section{Dormancy overcoming inDesmodium tortuosum seeds}

In order to obtain a process capable of speeding the germination of D. tortuosum ( $S w$.) DC. seeds, two experiments were conducted with one-seeded loment (control) segments submitted to manual threshing; manual threshing followed by chemical scarification, also manual, with sandpaper $\mathrm{n}^{\circ} 220$; mechanical threshing (home processor); chemical scarification with $\mathrm{H}, \mathrm{S} 0$, (95\%) for 1,5 , and $8 \mathrm{~min}$; pre-heating at $53^{\circ} \mathrm{C}$ for 4,10 , and $16 \mathrm{~h}$ in forced-air oven; imbibition with $\mathrm{H}_{2} \mathrm{O}$ at $80^{\circ} \mathrm{C}$ for $1,3,5$, and $10 \mathrm{~min} ; \mathrm{H} 20$ at $27 \mathrm{oC}$ for $2 \mathrm{~h}$; and imbibition with thermal swich $\left(\mathrm{H}_{2} \mathrm{O}\right.$

1Recebido para publicação em 04/08/97 na forma revisada em 11/12/97.

2Engenheiro Agrônomo, Dr., Depto Agricultura e Melhoramento Vegetal, FCA/UNESP, Caixa Postal 237 - Botucatu-SP.

3 Engenheiro Agrônomo, Curso de pós-graduação em Agricultura/ FCA/UNESP, Caixa Postal 237- Botucatu-SP.

4 Professor Doutor, Depto Agricultura e Melhoramento Vegetal, FCA/UNESP, Caixa Postal 237- Botucatu-SP. 
at $80{ }^{\circ} \mathrm{C} / 5 \mathrm{~min}$ and $\mathrm{H} 20$ at $13^{\circ} \mathrm{C} / 1 \mathrm{~min}$ ). For treatment evaluation one used germination $(\mathrm{G})$, soil seedling emergence (E), first count of germination (FG), and emergence (FE) tests, germination (I.V.G.) and emergence (I.V.E.) speed index, and seed ling length (SL). A completely randomized block design with 4 replications of 100 (G, FG, I.V.G.) or 20 seeds (SL) per treatment in the first experiment, and 4 replications of 50 (G, FG, I.V.G.) or 100 seeds (E, FE, I.V.E.) per treat ment on the second experiment was used. In the first experiment, the treatments which showed a significant dormancy decrease (D) and consequent germination increase (G) in comparison with the control $(\mathrm{D}=82 \% ; \mathrm{G}=$ $15 \%)$ were, in a decreasing efficacy order: manual

\section{INTRODUÇÃO}

Desmodium tortuosum L. é uma espécie de planta nativa da América tropical e, a partir do final da década de 80, ganhou importância no Brasil como planta infestante de lavouras de soja nos estados de Mato Grosso do Sul, Mato Grosso, Goiás e Minas Gerais (Pereira, 1988 e Barros, 1990); provavelmente, devido ao controle ineficiente dos herbicidas utilizados e à adoção de baixas taxas de semeadura para a soja (Melhorança, 1994).

A dispersão dessa espécie ocorre por meio de sementes contidas nos frutos inteiros ou segmentados (lomentos com 4 a 6 artículos indeiscentes) ou de sementes nuas. Como a maioria das plantas daninhas, o D. tortuosum apresenta a germinação distribuída ao longo do tem po de vido à dormência das sementes. Estratégia essa, de invasão e sobrevivência, que permite à espécie superar condições ambientais de sfa vo rá veis. As sementes de ste gê ne ro apresentam dormência decorrente da impermeabilidade do tegumento, que é a causa mais comum de dormência nas sementes de leguminosas (Carvalho \& Nakagawa, 1983).

No entanto, existem vários tratamentos que podem ser usados para superar esse tipo de threshing and scarification ( $\mathrm{D}=3 \% ; \mathrm{G}=92 \%)$, mechanic al threshing ( $\mathrm{D}=13 \% ; \mathrm{G}=81 \%)$, imbibition in $\mathrm{H} 20$ at $80^{\circ} \mathrm{C}$ for $1 \mathrm{~min}(\mathrm{D}=68 \%$; $\mathrm{G}$ $=29 \%)$ and $3 \min (\mathrm{D}=65 \% ; \mathrm{G}=32 \%)$. The second experiment (control with $\mathrm{D}=93 \% ; \mathrm{G}=3 \%$ ) pointed out: threshing and manual scarification $(\mathrm{D}=2 \% ; \mathrm{G}=93 \%)$, mechanical threshing $(\mathrm{D}=2 \%$; $\mathrm{G}=87 \%$ ), imbibition into $\mathrm{H}_{2} \mathrm{O}$ at $80^{\circ} \mathrm{C}$ for $5 \mathrm{~min}$ and thermal switch (both with $\mathrm{D}=85 \%$ and $\mathrm{G}=$ $11 \%$ ). The FC, I.V.G., I.V.E., SL, and E vigour tests conf irmed these results. Thus, manual scarification with 220 sandpaper and mechanical threshing (with a processor) are recommended to overcome $D$. tortuosum seed dormancy.

Key words: weed, germination, emergence.

dormência, tais como: escarificação química com $\mathrm{H}_{2} \mathrm{SO}_{4}$ e em be bi ção em ág ua qu en te, como aplicados com eficácia em sementes de $D$. ovalifolium (Waidyanatha \& Ariyaratne, 1976; Rojas \& Herrera, 1989), D. tiliaefolium (Maithani et al., 1991) e D. intortum (Cabrales \& Bernal, 1983); e a escarificação por abrasão, o desponte ou impactos (Almeida et al., 1979; Maeda \& Lago, 19 86; Castro \& Carvalho, 1992). A ap licação e a eficiência desses tratamentos dependem da porcentagem da dormên cia, a qual está relacionada com a espécie, o lote e a idade da semente.

A germinação rápida e uniforme das sementes é de interesse para os estudos de manejo de plantas daninhas, principalmente para a aval iação de he rbicidas aplicados em pósemergência. O objetivo de ste trabal ho foi en contrar mé to dos práticos para su perar a dormência e promover a germinação de sementes de D. tortuosum. visando semeadura no campo.

\section{MATERIAL E MÉTODOS}

O presente trabalho constou de dois experimentos. No primeiro, buscou-se a seleção de tratamentos promis sores na supe ração da dormência das sementes de D. tortuosum, os quais 
foram aperfeiçoados e melhor explorados num segundo experimento, no qual também avaliou-se a semeadura no solo.

Os lomentos foram colhidos quando se apresentavam secos, retorcidos e em início de liberação dos artículos unis seminados e, no laboratório, foram manuseados para que houvesse uma total segmentação. A colheita foi realizada manualmente no final da safra de verão (segunda quinzena de março a primeira de abril de 1997) em uma área próxima ao Município de São
Pedro/SP, para o primeiro experimento, e em três áreas próximas à fazenda Barreiro Rico, na re gi ão de Botucatu/S P, para o se gundo; nesse último, as sementes foram homogeneizadas em partes iguais formando um único lote.

0s tratamentos testados para a superação da dormência no primeiro e no segundo experimento estão descritos nas Tabelas 1 e 2, respectivamente. Para detectar o efeito dos tratamentos foram realizados os seguintes testes de qualidade:

TABELA 1. Denominação e descrição dos tratamentos aplicados às sementes de Desmodium tortuosum no primeiro experimento. Botucatu/SP, 1997.

\begin{tabular}{|c|c|}
\hline Denominação & Descrição \\
\hline Testemunha & Segmento de lomento intacto unisseminado e sem tratamento. \\
\hline Debulha manual & Liberação da semente pela remoção manual do segmento de lomento. \\
\hline Escarificação manual & Semente debulhada e escarificada manualmente em lixa $n^{\circ} 220$ por 7 segundos. \\
\hline Debulha mecânica & $\begin{array}{l}\text { Liberação da semente pela remoção mecânica do segmento de lomento em processador } \\
\text { doméstico de alimentos da marca Arno. Peneirar a cada } 6 \text { pulsações de } 1 \text { segundo para retirar } \\
\text { as sementes nuas. }\end{array}$ \\
\hline $\mathrm{H}_{2} \mathrm{O} 80^{\circ} \mathrm{C} / 1 \mathrm{~min}$ & $\begin{array}{l}\text { Segmento de lomento unisseminado imerso em água quente por } 1 \text { minuto (temperatura } \\
\text { inicial de } 80^{\circ} \mathrm{C} \text { e final de } 61^{\circ} \mathrm{C} \text { ), lavada em água corrente }\left(27^{\circ} \mathrm{C}\right) \text { e deixado secar à sombra. }\end{array}$ \\
\hline $\mathrm{H}_{2} \mathrm{O} 80^{\circ} \mathrm{C} / 3 \mathrm{~min}$ & $\begin{array}{l}\text { Segmento de lomento unisseminado imerso em água quente por } 3 \text { minutos (temperatura } \\
\text { inicial de } 80^{\circ} \mathrm{C} \text { e final de } 62^{\circ} \mathrm{C} \text { ), lavada em água corrente }\left(27^{\circ} \mathrm{C} \text { ) e deixado secar à sombra. }\right.\end{array}$ \\
\hline $\mathrm{H}_{2} \mathrm{O} / 2 \mathrm{~h}$ & $\begin{array}{l}\text { Segmento de lomento unisseminado imerso em água à temperatura ambiente }\left(27^{\circ} \mathrm{C}\right) \text { trocada } \\
\text { a intervalos de meia hora por } 2 \text { horas e deixado secar à sombra. }\end{array}$ \\
\hline $\mathrm{H}_{2} \mathrm{SO}_{4} / 1 \mathrm{~min}$ & $\begin{array}{l}\text { Segmento de lomento unisseminado imerso em ácido sulfúrico }(36 \mathrm{~N}, 95 \%) \text { por } 1 \text { minuto e } \\
\text { lavado em água corrente e deixado secar à sombra. }\end{array}$ \\
\hline $\mathrm{H}_{2} \mathrm{SO}_{4} / 5 \mathrm{~min}$ & $\begin{array}{l}\text { Segmento de lomento unisseminado imerso em ácido sulfúrico }(36 \mathrm{~N}, 95 \%) \text { por } 5 \text { minutos e } \\
\text { lavado em água corrente e deixado secar à sombra. }\end{array}$ \\
\hline $\mathrm{H}_{2} \mathrm{SO}_{4} / 8 \mathrm{~min}$ & $\begin{array}{l}\text { Segmento de lomento unisseminado imerso em ácido sulfúrico }(36 \mathrm{~N}, 95 \%) \text { por } 8 \text { minutos e } \\
\text { lavado em água corrente e deixado secar à sombra. }\end{array}$ \\
\hline $53^{\circ} \mathrm{C} / 4 \mathrm{~h}$ & $\begin{array}{l}\text { Segmento de lomento unisseminado mantido por } 4 \text { horas em estufa com circulação forçada } \\
\text { de ar à temperatura de } 53^{\circ} \mathrm{C} \text {. }\end{array}$ \\
\hline $53^{\circ} \mathrm{C} / 10 \mathrm{~h}$ & $\begin{array}{l}\text { Segmento de lomento unisseminado mantido por } 10 \text { horas em estufa com circulação forçada } \\
\text { de ar à temperatura de } 53^{\circ} \mathrm{C} \text {. }\end{array}$ \\
\hline $53^{\circ} \mathrm{C} / 16 \mathrm{~h}$ & $\begin{array}{l}\text { Segmento de lomento unisseminado mantido por } 16 \text { horas em estufa com circulação forçada } \\
\text { de ar à temperatura de } 53^{\circ} \mathrm{C} \text {. }\end{array}$ \\
\hline
\end{tabular}


TABELA 2. Denominação e descrição dos tratamentos aplicados nos lotes de sementes de Desmodium tortuosum no segundo experimento. Botucatu/SP, 1997.

\begin{tabular}{|c|c|}
\hline Denominação & Descrição \\
\hline Testemunha & Segmento de lomento intacto unisseminado e sem tratamento. \\
\hline Debulha manual & Liberação da semente pela remoção manuai do segmento de lomento. \\
\hline Escarificação manual & Semente debulhada e escarificada manualmente em lixa $n^{\circ} 220$ por 4 segundos. \\
\hline Debulha mecânica & $\begin{array}{l}\text { Liberação da semente pela remoção mecânica do segmento de lomento em processador } \\
\text { doméstico de alimentos da marca Arno. Peneirar a cada } 3 \text { pulsações de } 1 \text { segundo para retirar } \\
\text { as sementes nuas. }\end{array}$ \\
\hline $\mathrm{H}_{2} \mathrm{O} 80^{\circ} \mathrm{C} / 5 \mathrm{~min}$ & $\begin{array}{l}\text { Segmento de lomento unisseminado imerso em água quente por } 5 \text { minutos (temperatura } \\
\text { inicial de } 80^{\circ} \mathrm{C} \text { e final de } 66^{\circ} \mathrm{C} \text { ), lavada em água corrente }\left(25^{\circ} \mathrm{C}\right) \text { por } 1 \mathrm{~min} \text { e deixado secar à } \\
\text { sombra. }\end{array}$ \\
\hline $\mathrm{H}_{2} \mathrm{O} 80^{\circ} \mathrm{C} / 10 \mathrm{~min}$ & $\begin{array}{l}\text { Segmento de lomento unisseminado imerso em água quente por } 10 \text { minutos (temperatura } \\
\text { inicial de } 80^{\circ} \mathrm{C} \text { e final de } 62^{\circ} \mathrm{C} \text { ), lavada em água corrente }\left(25^{\circ} \mathrm{C}\right) \text { por } 1 \text { min e deixado secar à } \\
\text { sombra. }\end{array}$ \\
\hline Alternância térmica & $\begin{array}{l}\text { Segmento de lomento unisseminado imerso em água quente por } 5 \text { minutos (temperatura } \\
\text { inicial de } 80^{\circ} \mathrm{C} \text { e final de } 65^{\circ} \mathrm{C} \text { ), lavada em água fria por } 1 \mathrm{~min} \text { (temperatura inicial de } 13^{\circ} \mathrm{C} \mathrm{e} \\
\text { final de } 16^{\circ} \mathrm{C} \text { ) e deixado secar à sombra. }\end{array}$ \\
\hline
\end{tabular}

\section{Teste de germinação:}

Foi conduzido, com 100 e 50 sementes por repetição para o primei ro e o se gundo experimento, respectivamente, sob temperatura constante de $30^{\circ} \mathrm{C}$ sobre duas folhas de papel tipo filtro umedecidos com $12 \mathrm{ml}$ de água destilada (Brasil, 1992). A contagem das plântulas foi realizada até os 28 dias quando foram calculadas as porcentagens de ge rmin ação (plântulas normais), de plântulas anormais, de sementes dormentes (duras) e de sementes mortas.

\section{Primeira contagem de germinação:}

Foi realizada considerando a porcentagem de plântulas normais (Brasil, 1992) presentes no teste de germinação no sétimo dia após a semeadura para ambos experimentos.

\section{Índice de Velocidade de Germinação(I.V.G.):}

Foi realizado conjuntamente com o teste de germinação, utilizando-se o critério estabelecido por Maguire (1962). Foram contadas, diariamente, as plântulas normais germinadas dos 3 aos 28 e dos 4 aos 28 dias após a instalação do teste, respectivamente, para o primeiro e o segundo experimento.

\section{Comprimento de plântula:}

As sementes, em nú me ro de 20 por repetição, foram semeadas alinhadas sobre duas folhas de papel toalha umedecidas com 2,5 vezes o peso do papel em água. 0s rolos de papel foram acondicionados em sacos plásticos vedados e mantidos à temperatura de $30^{\circ} \mathrm{C}$ constante por 20 dias, quando foram avaliados o comprimento $(\mathrm{cm})$ da parte aérea (colo-meristema apical); da radícula (colo-meristema radicular); e total da plântula (meristema apical-meristema radicular). Foi considerada, para o cál culo da média de cada repetição, a população total de sementes. Esse teste foi realizado apenas no primeiro experimento.

\section{Emergência em solo:}

As sementes, em número de 100 por repetição, foram semeadas a $0,5 \mathrm{~cm} \mathrm{de}$ profundidade em solo peneirado e acondicionado em caixas de 6 litros, em condição ambiente de casa de vegetação. For am considerada s como emersas as plântulas que apresentavam mais de 1 
$\mathrm{cm}$ de parte aérea acima do solo. A contagem foi realizada diariamente até os 30 dias após a semeadura, quando foi determinada a porcentagem de plântulas emersas. A temperatura ambiente máxima e mínima média diária, respectivamente, durante o período foi de $36^{\circ} \mathrm{C}$ e $19,7{ }^{\circ} \mathrm{C}$. Es se teste foi realizado apen as no segundo experimento.

\section{Primeira contagem de emergência:}

Foi realizada considerando a porcentagem de plântulas emersas presentes no teste de em er gência em solo no décimo dia após a semeadura.

\section{Índice de Velocidade de Emergência (I.V.E.):}

Foi realizado conjuntamente com o teste de emergência em solo, utilizando o critério estabelecido por Maguire (1962). Foram contadas, diariamente, as plântulas emersas dos 10 aos 30 dias após a semeadura.

\section{Teor de água:}

Foi avaliado, a $105 \pm 3^{\circ} \mathrm{C} / 24 \mathrm{~h}$, pelo método da estufa (Brasil, 1992). 0s dados de teor de água das sementes após a aplicação dos tratamentos foram corrigidos, quando necessário, por meio de reidratação para aproximadamente $12 \%$ no primeiro experimento e $7 \%$ no segundo, utilizando-se as testemunhas como padrões referenciais. Isso foi realizado para isentar as avaliaçõe s fisiológica dos ef eitos que as diferenças de teor de água entre os tratamentos poderiam provocar no processo de embebição.

0 delineamento experimental utilizado foi $\mathrm{o}$ inteiramente casualizado com os tratamentos em quatro repetições. Foi efetuada a análise de variância pelo teste $\mathrm{F}$ e a comparação das médias dos tratamentos foi efetuada pelo teste $\mathrm{t}(5 \%)$.

\section{RESULTADOS E DISCUSSÃO}

0s tratamentos de embebição em $\mathrm{H} 20$ / 2h, de escarificação química em $\mathrm{H}_{2} \mathrm{SO}_{4} / 1$ min e de pré-aquecimento $\left(53^{\circ} \mathrm{C} / 4,10\right.$ e $\left.16 \mathrm{~h}\right)$ diminuiram a taxa de germinação por terem induzido a dormência das sementes de D. tortuosum (Tabela 3). A utilização do pré-aquecimento apresenta o inconveniente de induzir a dormência, caso a tempe rat ura não seja suficientemente alt a e o período de exposição seja inadequado à espécie es tu dada (Mott \& McKeon, 1979). Contudo, quando aplicado adequadamente, pode promover a superação da dormência e a germinação das sementes de leguminosas, tais como Desmodium ovalifolium (Rojas \& Herrera, 1989), Pueraria phaseoloides (Almeida et al., 1979) e Stylosanthes hamata (Mott \& McKeon, 1979). Pouco se sabe a re spei to dos meca ni smos bi oquímic os que regu lam a resposta fisiológica das sementes ao calor, mas supõe-se que temperaturas mais elevad as por menor tempo poderiam surtir resultados mais promissores na superação da dormência de D. tortuosum do que os obtidos nesse experimento.

Embora hajam evidências de que a dormência de sementes de Desmodium spp. possa est ar ligada às su bstân ci as inibi do ras de germinação (Rojas \& Herrera, 1989; Maithani et. al., 1991), a embebição das sementes em água na temperatura ambiente por apenas 2 horas mostrouse insuficiente para diluir ou lixiviar essas substâncias e superar a dormência (Tabela 3). Maithani et. al. (1991), para superar a dormência de $D$. tiliaefolium, utilizaram $48 \mathrm{~h}$ de embebição. Maeda \& Lago (1986) embeberam durante $72 \mathrm{~h}$ sementes de Styzolobium atterrimum, no entanto com efeitos inóquos. Adicional mente, o processo de embebição e secagem induziu a dormência nas sementes que apresentavam tegumento, inicialmente, permeável (Tabela 3).

A escarificação química em $\mathrm{H}_{2} \mathrm{SO}_{4} / 5$ e 8 min não foi capaz de implementar a germinação e causou danos promotores de anormalidades nas plântulas e mortalidade de sementes (Tabela 3), apesar do tratame nto $\mathrm{H}_{2} \mathrm{SO}_{4} / \mathrm{O} 5 \mathrm{~min}$ ter promovido a superação da dormência. Os testes da primeira contagem de germinação, do I.V.G. e do comprimento de plântula não detectaram efeitos da escarificação química sobre o vigor das sementes em comparação à testemunha; exceção fe it a ao $\mathrm{H}_{2} \mathrm{SO}_{4} / 8 \mathrm{~min}$, que implementou o comprimento da parte aérea da plântula. 
0 tratamento de escarificação química, além de apresentar riscos operacionais aos trabalhadores e ao ambiente, mostrou-se de difícil adequação às sementes de D. tortuosum, que por particularidades estruturais, foram facilmente danificadas pelo processo. A escarificação química de sementes de Desmodium spp. em $\mathrm{H}_{2} \mathrm{SO}_{4}$ pode ocasionar resultados inconsistentes quanto à superação da dormência (Johnston,
1981), mas alguns trabalhos recomendam o procedimento (Waidyanatha \& Ariyaratne, 1976; Cabrales \& Bernal, 1983; Rojas \& Herrera, 1989). A eficácia desse tratamento depende do tempo de imersão e de características intrínsecas da espécie a ser trabalhada, tais como: a espessura e a composição química das células dos tecidos de revestimento da semente (Rojas \& Herrera, 1989; Maithani et al., 1991).

TABELA 3. Germinação, dormência, plântulas an ormais, mortalidade, primeira contagem de germinação, índice de velocidade de germinação (I.V.G.) e comprimento de plântula de Desmodium tortuosum cujas sementes foram submetidas a tratamentos físicos, químicos e térmicos no primeiro experimento. Botucatu/ SP, 1997.

\begin{tabular}{|c|c|c|c|c|c|c|c|c|c|}
\hline \multirow[t]{2}{*}{ Tratamentos } & \multirow[t]{2}{*}{ Germinação } & \multirow[t]{2}{*}{ Dormència } & \multirow{2}{*}{$\begin{array}{c}\text { Plântulas } \\
\text { anormais } \\
\%\end{array}$} & \multirow[t]{2}{*}{ Mortalidade } & \multirow{2}{*}{$\begin{array}{c}\text { Primeira } \\
\text { contagem de } \\
\text { germinaçầo }\end{array}$} & \multirow[t]{2}{*}{ I.V.G. } & \multicolumn{3}{|c|}{$\begin{array}{l}\text { Comprimento de plântula } \\
\qquad(\mathrm{cm})\end{array}$} \\
\hline & & & & & & & $\begin{array}{l}\text { Parte } \\
\text { aérea }\end{array}$ & Radícula & Total \\
\hline Testemunha & $15,0 \mathrm{e}$ & $82,5 \mathrm{c}$ & $0,0 \mathrm{c}$ & $2,5 \mathrm{~b}$ & $1,2 \mathrm{c}$ & $0,92 \mathrm{def}$ & $0,20 \mathrm{e}$ & 0,18 ef & $0,38 \mathrm{efg}$ \\
\hline Debulha manual & $19,0 \mathrm{ed}$ & $78,7 \mathrm{c}$ & $0,0 \mathrm{c}$ & $2,2 \mathrm{~b}$ & $1,5 \mathrm{c}$ & $1,25 \mathrm{de}$ & 0,42 de & $0,42 \mathrm{de}$ & 0,85 def \\
\hline Escarificação manual & 91,5 a & $2,7 \mathrm{~g}$ & $0,0 \mathrm{c}$ & $5,7 \mathrm{a}$ & 24,2 a & 9,86 a & $4,72 \mathrm{a}$ & 4,86 a & $9,58 \mathrm{a}$ \\
\hline Debulha mecânica & $80,7 \mathrm{~b}$ & $12,7 \mathrm{f}$ & $1.3 \mathrm{a}$ & $5,2 \mathrm{a}$ & $17,7 \mathrm{~b}$ & $7,74 \mathrm{~b}$ & $3,19 \mathrm{~b}$ & $2,56 \mathrm{~b}$ & $5,76 \mathrm{~b}$ \\
\hline $\mathrm{H}_{2} \mathrm{O} 80^{\circ} \mathrm{C} / 1 \mathrm{~min}$ & $29,0 \mathrm{c}$ & $68,0 \mathrm{e}$ & $0,5 \mathrm{~b}$ & $2,5 \mathrm{~b}$ & $1,7 \mathrm{c}$ & $2,21 \mathrm{c}$ & $0,94 \mathrm{c}$ & $0,95 \mathrm{c}$ & $1,89 \mathrm{c}$ \\
\hline $\mathrm{H}_{2} \mathrm{O} 80^{\circ} \mathrm{C} / 3 \mathrm{~min}$ & $32,5 \mathrm{c}$ & $65,5 \mathrm{e}$ & $0,0 \mathrm{c}$ & $2,0 \mathrm{~b}$ & $4,0 \mathrm{c}$ & $2,50 \mathrm{c}$ & $0,92 \mathrm{c}$ & $0,58 \mathrm{c}$ & $1,51 \mathrm{~cd}$ \\
\hline $\mathrm{H}_{2} \mathrm{O}$ ambiente $/ 2 \mathrm{~h}$ & $5,2 \mathrm{fg}$ & $93,2 \mathrm{ab}$ & $0,0 \mathrm{c}$ & $1,5 \mathrm{~b}$ & $1,7 \mathrm{c}$ & $0,56 \mathrm{efg}$ & $0,24 \mathrm{de}$ & $0,24 \mathrm{def}$ & $0,47 \mathrm{efg}$ \\
\hline $\mathrm{H}_{2} \mathrm{SO}_{4} / 1 \mathrm{~min}$ & $7,0 \mathrm{f}$ & $90,7 \mathrm{~b}$ & $0.0 \mathrm{c}$ & $2,2 \mathrm{~b}$ & $0,5 \mathrm{c}$ & $0,53 \mathrm{fg}$ & $0,09 \mathrm{e}$ & $0,10 \mathrm{ef}$ & $0,19 \mathrm{fg}$ \\
\hline $\mathrm{H}_{2} \mathrm{SO}_{4} / 5 \mathrm{~min}$ & $20,2 \mathrm{de}$ & $74,5 \mathrm{~d}$ & $0.5 \mathrm{~b}$ & $4,7 \mathrm{a}$ & $0,7 \mathrm{c}$ & $1,33 \mathrm{~d}$ & $0,43 \mathrm{de}$ & $0,29 \mathrm{def}$ & 0,72 defg \\
\hline $\mathrm{H}_{2} \mathrm{SO}_{4} / 8 \mathrm{~min}$ & $16,7 \mathrm{de}$ & $77,7 \mathrm{~cd}$ & $0.5 \mathrm{~b}$ & $5,0 \mathrm{a}$ & $0,0 \mathrm{c}$ & $1,25 \mathrm{de}$ & $0,66 \mathrm{~cd}$ & $0,37 \mathrm{def}$ & $1,03 \mathrm{de}$ \\
\hline $53^{\circ} \mathrm{C} / 4 \mathrm{~h}$ & $1.5 \mathrm{~g}$ & 96,0 a & $0.0 \mathrm{c}$ & $2,5 \mathrm{~b}$ & $0,0 \mathrm{c}$ & $0,09 \mathrm{~g}$ & $0.09 \mathrm{e}$ & $0,15 \mathrm{ef}$ & $0,24 \mathrm{efg}$ \\
\hline $53^{\circ} \mathrm{C} / 10 \mathrm{~h}$ & $3.7 \mathrm{fg}$ & $94,0 \mathrm{ab}$ & $0.0 \mathrm{c}$ & $2,2 \mathrm{~b}$ & $1,0 \mathrm{c}$ & $0,34 \mathrm{fg}$ & $0,02 \mathrm{e}$ & $0,02 \mathrm{f}$ & $0,04 \mathrm{~g}$ \\
\hline $53^{\circ} \mathrm{C} / 16 \mathrm{~h}$ & $0,7 \mathrm{~g}$ & $97,0 \mathrm{a}$ & $0,0 \mathrm{c}$ & $2,2 \mathrm{~b}$ & $0,0 \mathrm{c}$ & $0,05 \mathrm{~g}$ & $0,05 \mathrm{e}$ & 0,03 ef & $0,08 \mathrm{fg}$ \\
\hline $\mathrm{F}$ & $314,07^{* *}$ & $437,59^{* *}$ & $6,00^{* *}$ & $4,05^{* *}$ & $25,61 * *$ & $148,27^{* *}$ & $86,08^{* *}$ & $98,21^{* *}$ & $97,98 * *$ \\
\hline C.V. $(\%)$ & 13.20 & 4,03 & 146,59 & 47,19 & 72,12 & 22,77 & 33,19 & 33,68 & 32,25 \\
\hline d.m.s. & 4,69 & 4,16 & 0,44 & 1,96 & 4,33 & 0,72 & 0,44 & 0,40 & 0,81 \\
\hline
\end{tabular}

** Significativo ao nivel de $1 \%$ de probabilidade.

Médias seguidas de mesma letra na coluna não diferem estatisticamente entre si pelo teste $t(\mathrm{P}>0,05)$.

Planta Daninha, v. 15, n. 2, 1997. 
A escarificação manual e a debulha mecânica, essa última em menor intensidade, aceleraram a velocidade da germinação, como pode ser verificado no teste da primeira contagem e no I.V.G. (Tabela 3). Em menor intensidade e apesar de não haverem superado estatisticamente a testemunha no teste da primeira contagem, os tratamentos de embebição em $\mathrm{H} 2080^{\circ} \mathrm{C}(1$ e 3 min) também tenderam a acelerar a germinação, como pode ser verificado pelo I.V.G.. 0 préaquecimento $\left(53^{\circ} \mathrm{C} / 4 \mathrm{e} 16 \mathrm{~h}\right)$ reduziu o I.V.G.

No primeiro experiment ofoi possível, também, verificar estímulos ao crescimento das plântulas devido à escarificação manual, à debulha mecânica e à embebição em $\mathrm{H}_{2} 080^{\circ} \mathrm{C}(1$ e 3 min), em ordem decrescente de estímulo, de modo semelhante ao verificado no teste de germinação. Para sementes de D. ovalifolium ( $\mathrm{Roj}$ as \& Herrera, 1989) e D. tiliaefolium (Maithani et al., 1991) a embebição em água fervente também promoveu a superação da dormência e a germinação.

No primeiro experimento (Tabela 3) os tratamentos que provocaram maior redução da dor mê nc ia e el evação da ge rmi na çã o em comparação à testemunha foram, em ordem decrescente: escarificação manual, debulha mecânica, $\mathrm{H}_{2} 080^{\circ} \mathrm{C} / 1$ min e $\mathrm{H}_{2} 080^{\circ} \mathrm{C} / 3 \mathrm{~min}$. Desse modo, os tratamentos de embebição em $\mathrm{H}_{2} \mathrm{O} / 2 \mathrm{~h}$, de escarificação química $\left(\mathrm{H}_{2} \mathrm{SO}_{4} / 1,5 \mathrm{e}\right.$ $8 \mathrm{~min})$ e de pré-aquecimento $\left(53^{\circ} \mathrm{C} / 4,10\right.$ e $\left.16 \mathrm{~h}\right)$ não foram utilizados no experimento seguinte por não apresentarem respostas favoráveis à germinação.

Os dois experimentos (Tabelas 3 e 4 ) demonstraram que a debulha manual não alterou as taxas de dormência, germinação, velocidade de germinação e de emergência, o crescimento da plântula e a emergência em solo em comparação à testemunha com sementes revestidas, demonstrando que a dormência em sementes de $D$. tortuosum não está relacionada à presença do segmento de lomento revestindo a semente e que o proces so de germinação não é af etado pe la presença dessa estrutura.
Tratamentos que resultam em lesões do tegumento das sementes, tais como a escarificação manual (arranhões) e a debulha mecânica (trincas e quebras), promovem a superação da dormência das sementes de D. tortuosum por permitirem a embebição das sementes e o início do processo de ge rmi na çã o. Re sultad os si m ilar es for am observados em sementes de Centrosema pubescens (Almeida et al., 1979), Styzolobium atterrimum (Maeda \& Lago,1986) e Lotus corniculatus (Castro \& Carvalho, 1992). No entanto, alguns cuidados devem ser tomados na intensidade e forma de aplicação desses tratamentos (Almeida et al., 1979; Maeda \& Lago, 1986; Castro \& Carvalho, 1992) para que as le sõ es não causem a re dução do vi gor das sementes e a elevação das taxas de infecção por fungos e bactérias, de anormalidades de plântulas e de mortalidade de sementes.

O somatório das taxas de plântulas anormais e de mortalidade representa a frequência populacional das sementes que, desprovidas de dormência, não se mostraram aptas a originar plântula s normai s. Na s co mparações com a testemunha, o primeiro experimento apresentou elevação nas taxas de plântulas anormais, devido a de bu lha mecânica e a em be bição em H20 $80^{\circ} \mathrm{C} / 1 \mathrm{~min}$; e de mortalidade, promovida pela escarificação manual e debulha mecânica (Tabela $3)$. Por isso, do primeiro para o segundo experimento, diminuiu-se de 7 para 4 segundos o tempo de escarificação manual em lixa e de 6 para 3 o número de pulsações no processador (Tabelas 1 e 2). Esse procedimento permitiu minimizar signif ic ativamente o ef eito da escarificação manual e da debulha mecânica sobre a mortalidade das sementes, em comparação à testemunha, mas não o efeito da debulha mecânica sobre a taxa de plântulas anormais, na maior parte infectadas (Tabelas 3 e 4). Em ambos experimentos deve-se ressaltar que a escarificação manual e a debulha mecânica, apesar de terem elevado as taxas de anormalidades e/ou mortalidade, o fizeram de forma suficientemente branda para permitir a superioridade desses 
tratamentos, em relação à testemunha, no teste de germinação.

No segundo experimento (Tabela 4) buscou-se, sem sucesso, melhorar a eficiência do tratamento de embebição em $\mathrm{H}_{2} \mathrm{O} \quad 80^{\circ} \mathrm{C}$ ampliando-se o tempo de embebição para 5 e 10 minutos e testando-se um choque térmico após a embebição por 5 minutos. A utilização de água aquecida vis ou promover o amolecimento dos tecidos e acelerar as reações físiológicas do tegumento das sementes, favorecendo a absorção de água, trocas gasosas e a ge rminação. 0 tratamento de embebição em $\mathrm{H}_{2} 080^{\circ} \mathrm{C} / 10 \mathrm{~min}$ não alterou a germinação, dormência ou vigor. A embebição em $\mathrm{H}_{2} \mathrm{O} 80^{\circ} \mathrm{C} / 5$ min e a embebição com alternância térmica, em valores semelhantes, superaram a dormência e elevaram a germinação e a velocidade de ge rminação (I.V.G.) em comparação à testemunha, mas na semeadura em solo, apenas o $\mathrm{H}_{2} \mathrm{O} 80^{\circ} \mathrm{C} / 5 \mathrm{~min}$ resultou em emergência e velocidade de emergência superiores às da testemunha.

TABELA 4. Germinação, dormência, plântulas anormais, mortalidade, primeira contagem de germinação, índice de velocidade de germinação (I.V.G.), emergência, primeira contagem de emergência e índice de velocidade de emergência (I.V.E.) de Desmodium tortuosum cujas sementes foram submetidas a tratamentos físicos, químicos e térmicos no segundo experimento. Botucatu/ SP, 1997.

\begin{tabular}{|c|c|c|c|c|c|c|c|c|c|}
\hline \multirow[t]{2}{*}{ Tratamentos } & Germinaçẫo & Dormència & $\begin{array}{l}\text { Plântulas } \\
\text { anormais }\end{array}$ & Mortalidade & $\begin{array}{c}\text { Primeira } \\
\text { contagem de } \\
\text { germinaçà̀o }\end{array}$ & \multirow[t]{2}{*}{ I.V.G } & Emergència & $\begin{array}{c}\text { Primeira } \\
\text { contagem de } \\
\text { emergència }\end{array}$ & \multirow[t]{2}{*}{ I.V.E. } \\
\hline & \multicolumn{5}{|c|}{$(\%)$} & & \multicolumn{2}{|c|}{$(\%)$} & \\
\hline Testemunha & $3,0 \mathrm{de}$ & $93.5 \mathrm{a}$ & $0.5 \mathrm{~b}$ & 3.0 & $1,5 \mathrm{de}$ & $0,21 \mathrm{~d}$ & $2.0 \mathrm{~d}$ & $0,5 \mathrm{c}$ & $0,13 \mathrm{~d}$ \\
\hline Debulha manual & $1,5 \mathrm{e}$ & $92,5 \mathrm{a}$ & $0.5 \mathrm{~b}$ & 5.5 & $0.5 \mathrm{e}$ & $0,08 \mathrm{~d}$ & $2,0 \mathrm{~d}$ & $1.5 \mathrm{c}$ & $0,17 \mathrm{~cd}$ \\
\hline Escarificaçăo manual & $93.5 \mathrm{a}$ & $1,5 \mathrm{c}$ & $0.5 \mathrm{~b}$ & 4,5 & 87,0 a & $8,74 \mathrm{a}$ & 53,5 a & $28,2 \mathrm{a}$ & $4,08 \mathrm{a}$ \\
\hline Debulha mecânica & $87,0 \mathrm{~b}$ & $2,5 \mathrm{c}$ & $5,5 \mathrm{a}$ & 5,0 & $79,0 \mathrm{~b}$ & $7,71 \mathrm{~b}$ & $41,7 \mathrm{~b}$ & $19,7 \mathrm{~b}$ & $3,13 \mathrm{~b}$ \\
\hline $\mathrm{H}_{2} \mathrm{O} 80^{\circ} \mathrm{C} / 5 \mathrm{~min}$ & $11.0 \mathrm{c}$ & $85,0 \mathrm{~b}$ & $0.5 \mathrm{~b}$ & 3.5 & $7,0 \mathrm{c}$ & $0,83 \mathrm{c}$ & $8.2 \mathrm{c}$ & $4,5 \mathrm{c}$ & $0,64 \mathrm{c}$ \\
\hline $\mathrm{H}_{2} \mathrm{O} 80^{\circ} \mathrm{C} / 10 \mathrm{~min}$ & $7.0 \mathrm{~cd}$ & $89,5 \mathrm{ab}$ & $0.5 \mathrm{~b}$ & 3,0 & $2.5 \mathrm{de}$ & $0.44 \mathrm{~cd}$ & $7.5 \mathrm{~cd}$ & $2,5 \mathrm{c}$ & $0.59 \mathrm{~cd}$ \\
\hline Alternância térmica & $11.5 \mathrm{c}$ & $85,0 \mathrm{~b}$ & $0.5 \mathrm{~b}$ & 3,0 & $5,0 \mathrm{~cd}$ & $0.67 \mathrm{c}$ & $5,7 \mathrm{~cd}$ & $3,2 \mathrm{c}$ & $0.49 \mathrm{~cd}$ \\
\hline $\mathrm{F}$ & $625,45^{* *}$ & $517,43^{* *}$ & $10.34^{* *}$ & $1,29^{\text {n.s. }}$ & $756.72 * *$ & $588,20^{* *}$ & $111,24^{* *}$ & $41.67^{* *}$ & $86.54^{* *}$ \\
\hline C.V. $(\%)$ & 10.68 & 5.84 & 96.78 & 47.46 & 10.88 & 11.79 & 23,27 & 39,13 & 26.01 \\
\hline d.m.s. & 4.81 & 5,51 & 1.73 & 2,74 & 4,17 & 0.46 & 5,90 & 4.95 & 0,50 \\
\hline
\end{tabular}

** Significativo ao nivel de $1 \%$ de probabilidade. NS Não significativo.

Médias seguidas de mesma letra na coluna não diferem estatisticamente entre si pelo teste $t(P>0,05)$.

Os tratamentos de embebição em água aquecida pelo período de até 5 minutos (Tabela 3 e 4), embora com menor eficiência que os tratamentos promotores de lesões físicas no tegumento, também aumentaram a germinação. Esse s resultados sugerem que maiores estudos devem ser realizados quanto à metodologia de administração de calor quando pretende-se superar a dormência de $D$. tortuosum utilizando-se calor e umidade, podendo-se trabalhar com as temperaturas e mantendo o tempo máximo de exposição de 5 min, pois exposições prolongadas a altas temperaturas podem causar a deterioração das sementes devido à desnaturação proteica e processos associados (Coolbear, 1994). 
No se gu ndo experimento, de modo semelhante ao primeiro, os tratamentos que provocaram maior redução da dormência e el evação da ge rmin ação em comparação à te stemunha foram, em or dem decrescente: esc arific ação manual, debulh a mecânica, H20 $80^{\circ} \mathrm{C} / 5 \mathrm{~min}$ e em be bi çã o co m al ter nância térmica. 0s testes de primeira contagem e de velocidade de germin ação, de eme rgência de plântulas em solo, de velocidade de germinação e de emergência corroboraram esse resultado. Conclui-se que os métodos de escarificação manual com lixa 220 e de bu lha mecânica, empregando-se processador, podem ser recomendados para a superação da dormência e promoção da germinação de sementes de $D$. tortuosum, visando a semeadura no campo.

\section{LITERATURA CITADA}

ALMEIDA, L.D., MAEDA, J.A., FALIVENE, S.M.P. Efeitos de métodos de escarificação manual na germinação de sementes de cinco leguminosas forrageiras. Bragantia, v.38, n.9, p.83-96, 1979.

BARR0S, A.C. Controle de plantas daninhas no cerrado. Agrotécnica, n.7, p.4-7, 1990.

BRASIL. Ministério da Agricultura. Regras para análise de sementes. Brasília: Departamen to Nacional de Prod ução Vegetal, Divisão de Sementes e Mudas, 1992.365p.

CARVALH0, N.M., NAKAGAWA, J. Sementes: Ciência, Tecnologia e Produção. Fundação Cargil, Campinas, 1983. 430 p.

CABRALES, R., BERNAL, J. Effect of different systems of seed treatment, packing, and storage on vigor and germination of five tropical forage legumes. In: INTERNATIONAL GRASSLAND CONGRESS, 14., Lexington, 1981.
Proceedings. Lexing ton: Smith, J.A., Hays, V.W., 1983. p.263-265.

CASTRO, R.T.C., CARVALHO, W.L. Superação da dormência tegumentar em sementes de comichão (Lotus corniculatus L.). Rev. Soc. Bras. Zootec., v.21, n.6, p.1009-1013, 1992.

C00LBEAR, P. Mechanisms of seed de te rior ation. In : Ba sra, A. S., Seed quality: basic mechanisms and agricultural implications. New york. Food Products Press, 1994. cap.8, p.223-277.

JOHNSTON, M.E.H. Report of the germination committee working group on tropical and sub-tropical seeds 1977-1980. Seed Sci. Technol., v.9, n.1, p.137-140, 1981.

MAEDA, J.A., LAG0, A.A. Germinação de sementes de mucuna-preta após tratamentos para superação da impermeabilidade do tegumento. Rev. Bras. Sem., v.8, n. 1, p.7984, 1986.

MAGUIRE, J.D. Speed of germination: aid in selection and evaluation for seedling emergence and vigor. Crop Sci., v.2, n.2, p. 176-177, 1962.

MAITHANI, G.P., BAHUGUNA, V.K., LAL, P. Seed germination behaviour of Desmodium tiliaefolium G.Don. -an important Shub species of himalayas. Indian For., v.117, n.8, p.593-595, 1991.

MELHORANÇA, A.L. Interferência entre plantas de Desmodium tortuosum ( $\mathrm{Sw}$ ) DC. e de Glycine $\max ($ L.) Merrill. Botucatu, 1994. 94 p. Tese (Doutorado) - Faculdade de Ciências Agrárias e Veterinárias, Universidade Estadual Paulista.

M0 TT, J., McKEON, G.M. Effect of he at treatments on breacking hard seedness in 
four species of Stylosantes. Seed Sci. Technol., v.7, p.87-98, 1979.

PEREIRA, F.A.R. Desmodium, uma ameaça à produção. Corr eio Agrícola, n.2, p.19-20, 1988.

ROJAS, S., HERRERA, J. Efecto de tratamientos físicos Y quimicos sobre el reposo de semillas de Desmodium ovalifolium. Agron. costarric., v.13, n.1, p.11-15, 1989.

WAIDYANATHA, U.P. de S., ARIYARATNE, W.A. Breaking dormancy in seeds of cover legumes. In: Journal of the Rubber Research Institute of Sri-Lanka, Sri-Lanka. v.53. p.8-16, 1976. Apud Abstracts on Tropical Agriculture, v.4, n.7, p.142, 1978. 